\title{
COMMENTARY
}

\section{Figuring out what works: a need for more and better studies on the relationship between ICU organization and outcomes}

\author{
Allan Garland* \\ See related research by Billington, et al., http://ccforum.com/content/13/6/R209
}

\begin{abstract}
Modifying how intensive care units (ICUs) are organized and run offers major opportunities to improve outcomes. In the previous issue of Critical Care, Billington and colleagues assessed the association of outcomes with intensivists' base speciality. However, very little is known about the relationships between ICU organization and outcomes. In the systems-based paradigm of quality improvement, every aspect of what we do and how we do it is a candidate for study and change. While we need much more rigorous research assessing every aspect of this large question, there are substantial barriers to conducting such studies.
\end{abstract}

In the previous issue of Critical Care, Billington and colleagues [1] presented an intriguing study assessing differences in intensive care unit (ICU) outcomes and resource use according to the base specialty of intensivists. While certain to be controversial, this type of research is important, and we need much more of it. But, first, details about the study itself.

This retrospective statistical analysis used data from three medical-surgical ICUs in Calgary, Alberta. All are closed ICUs, with house staff, and a single intensivist in charge for each block of time. Multivariable regression was used to evaluate the association of outcomes and resource use with the specialty training of their 26 intensivists. Specialties were divided into three groups: (a) internal medicine, (b) internal medicine and pulmonary subspecialty, or (c) all others, representing anesthesia, surgery, and emergency medicine.

*Correspondence: agarland@hsc.mb.ca

University of Manitoba Health Sciences Centre, 820 Sherbrook Street - GF222, Winnipeg, MB, Canada R3A 1R9
While not perfect, their analysis is appropriate, adjusting for the type and severity of illness and a number of other potentially confounding variables and using methods to deal with the intrinsically clustered data. They found some differences according to intensivist specialty, most prominent of which was that adjusted ICU mortality was significantly lower for patients under the care of those trained in internal medicine and pulmonary medicine. However, when all of their data were considered, the association between the intensivists' base specialty and outcomes was not very robust. As the authors indicate, these findings cannot be assumed to represent a causal pathway, and without additional studies they cannot be taken as either definitive or generalizable. However, it is completely plausible that such differences exist.

Variations in care and outcomes not related to patient or illness characteristics have been found throughout the health care system. Differences have been found at the level of geographic region [2], hospital [3], physician specialty, and individual physicians [4-6]. Widespread variation occurs in ICUs as well [5-9]. It is commonly recognized that different kinds of specialists do things differently. There is even evidence for personality trait differences among people in different specialties, and these differences in personality could influence practice styles $[10,11]$. And there is no obvious reason to believe that differences in practice could not translate to differences in outcomes and resource use.

Despite its narrow focus and admitted limitations, the paper by Billington and colleagues is important. It is important because it represents a serious effort to peer inside the black box of ICU organization and to understand a detail of how ICU organization influences outcomes.

With few of the diagnostic or therapeutic innovations in ICU care over recent decades having produced substantial improvements in outcomes, we must recognize that equal or greater opportunities to improve 
ICU care derive from improving the structures and processes that it consists of [12]. Outside of medicine, it is widely accepted that most of the opportunities to improve the performance of complex organizations derive from improving the structures and processes that they consist of. Although this vital concept is often ignored by physicians, it is not absent from the medical literature [13-15]. Within this systems-based concept, every aspect of what we do and how we do it is a candidate for study and change [12]; this list includes the training and organization of intensivists. With a virtual absence of information relating ICU training with ICU outcomes, many questions remain unanswered. Is there an optimal duration of training? What is the optimum training curriculum? Are outcomes of certain types of patients better under the care of intensivists with a certain base specialty or ICU training or both? The goal of asking these questions is not to exclude any sort of physician from the community of intensivists, but rather to work toward identifying the optimal way to train intensivists to ensure that all ICU care is as good as it can be.

But the matter of intensivists and their training is just one piece of this pie. Since little is known about the relationships between ICU organization and outcomes, we need much more and higher quality research assessing every aspect of ICU organization to uncover how we should organize ICU care to improve outcomes. And as with any other kind of research, we will need numerous studies from multiple sites to begin developing a consistent and integrated understanding of this complex topic. But there are steep barriers to conducting such studies. They are difficult to perform, get funded, and get published. The impediments to doing randomized controlled studies of organizational change in ICUs are commonly insurmountable. This and other practical considerations make it unfair to dismiss a study on this topic because it is a retrospective statistical analysis of what amounts to a natural experiment, or because it derives from one or a few centers, or because it failed to adjust for every potentially confounding variable that we can imagine, or because it feels threatening to one's professional sense of self. Lastly, to promote organizational research in health care, funding agencies need to recognize its importance and institute plans to support it.
Abbreviation

$\mathrm{ICU}=$ intensive care unit.

\section{Competing interests}

The author declares that he has no competing interests.

Published: 27 January 2010

References

1. Billington EO, Zygun DA, Stelfox HT, Peets AD: Intensivists' base specialty of training is associated with variations in mortality and practice patterns. Crit Care 2010, 13:R209.

2. Center for the Evaluative Clinical Sciences Staff: The Dartmouth Atlas of Health Care 1999. Chicago, IL: American Hospital Publishing; 1999.

3. Burns LR, Wholey DR: The effects of patient, hospital, and physician characteristics on length of stay and mortality. Med Care 1991, 29:251-271.

4. Greenfield S, Nelson EC, Zubkoff M, Manning W, Rogers W, Kravitz RL, Keller A, Tarlov AR, Ware JE: Variations in resource utilization among medical specialties and systems of care: results from the Medical Outcomes Study. JAMA 1992, 267:1624-1630.

5. Garland A, Connors AF: Physicians' influence over decisions to forego life support. J Palliat Med 2007, 10:1298-1305.

6. Garland A, Shaman Z, Baron J, Connors AF Jr.: Physician-attributable differences in intensive care unit costs: a single-center study. Am J Respir Crit Care Med 2006, 174:1206-1210.

7. Ferrand $E$, Robert R, Ingrand P, Lemaire F, French LATEREA Group: Withholding and withdrawal of life support in intensive-care units in France: a prospective survey. Lancet 2001, 357:9-14.

8. Rapoport J, Gehlbach S, Lemeshow S, Teres D: Resource utilization among intensive care patients: managed care vs. traditional insurance. Arch Intern Med 1992, 152:2207-2222

9. Rothen H, Stricker K, Einfalt J, Bauer P, Metnitz P, Moreno R, Takala J: Variability in outcome and resource use in intensive care units. Intensive Care Med 2007, 33:1329-1336.

10. Gerrity MS, Earp JAL, DeVellis RF, Light DW: Uncertainty and professional work: perceptions of physicians in clinical practice. Am J Sociol 1992, 97:1022-1051.

11. Merrill JM, Camacho Z, Laux LF, Lorimor R, Thornby JL, Vallbona C: Uncertainties and ambiguities: measuring how medical students cope. Med Educ 1994, 28:316-322.

12. Garland A: Improving the intensive care unit. Part 2. Chest 2005, 127:2165-2179.

13. Shortell SM, Singer SJ: Improving patient safety by taking systems seriously. JAMA 2008, 299:445-447.

14. Amalberti R, Auroy $Y$, Berwick D, Barach P: Five system barriers to achieving ultrasafe health care. Ann Intern Med 2005, 142:756-764.

15. Berwick DM: Continuous improvement as an ideal in health care. NEng/J Med 1989, 320:53-56

doi:10.1186/cc8843

Cite this article as: Garland A: Figuring out what works: a need for more and better studies on the relationship between ICU organization and outcomes. Critical Care 2010, 14:108. 